\title{
Perception and Production of English Front Vowels by Taiwanese EFL Learners
}

\author{
Ching-Ying Lin \\ Department of Applied English, National Pingtung Institute of Commerce, Taiwan
}

\begin{abstract}
The study aimed to compare the perception and production of English front vowel pairs: /i/-// / and $/ \varepsilon /-/ æ /$ and to identify their perception-production link by Taiwanese EFL learners through minimal-pair tests. Twenty Grade 6 elementary school students in Taiwan were randomly selected to be engaged in two tests with 4 front vowels $(/ \mathrm{i} /, / / /, / \varepsilon /$, /æ/) embedded in ten monosyllabic words respectively for perception and production. The results revealed that the performance of Taiwanese EFL learners on the /i/-/I /pair was significantly better than that on the $/ \varepsilon /$ /æ/ pair both in terms of perception and production. To be more specific, the participants perceived and produced /i/ significantly better than / /. The production performance of $/ \varepsilon$ / was significantly better than that of /æ/ whereas the perception performance of /æ/ was slightly better than that of $/ \varepsilon /$. A positive relationship between perception and production of these two front vowel pairs was also proven. Pedagogical implications of the study and suggestions for future studies were discussed in the end.
\end{abstract}

Index Terms - front vowels, vowel perception, vowel production

\section{INTRODUCTION}

Acquisition of the phonetic system plays a critical role on learning L2 communication (Ho, 2009). Speakers with good pronunciation can be understood by others more precisely. In other words, non-native speakers may easily feel frustrated and be misunderstood when they make conversation with native speakers because of the lack of L2 pronunciation accuracy and fluency. Phonetic research has shown that L1 interference caused the fluency lack of nonnative L2 pronunciation (Best, 1991). As for the errors resulting in pronunciation inaccuracy, they can be categorized into three types: phoneme error, stress error, and intonation error (Liao, 2006). Studies focused on perception and production of vowels and consonants have been put into practice for quite a long period of time. However, due to Communicative Language Teaching (CLT) that has been quite popular in Taiwan, teachers underscore students' interaction, communication and problem solving more than correct grammar and pronunciation. They give students great encouragement for talking in English and endure grammar and pronunciation errors. What the teachers do sounds ideal, in fact it really bring about some problems. When teachers ignore the pronunciation instruction and correction, students can't learn the native-like L2 language. Lin (1995) ever punctuated the instruction of native-like pronunciation in second language learning by mentioning "how can you communicate with people successfully if your pronunciation is incorrect?" (p.2). The importance of phonetic instruction, especially for EFL learners has received wide support among researchers.

In a nutshell, phoneme articulation is the foundation of L2 pronunciation accuracy. An experienced English teacher should be competent to identify and evaluate students' pronunciation performance. For helping students enhance their accurate perception and production of English phonemes, to examine students' pronunciation difficulties is necessary. Much research attention has been paid to the foreign accent leading to mispronouncing English words (Ho, 2009). He stated that without target accuracy, successful communication and interaction would be blocked. Fogerty and Humes (2011) even concluded that vowels contributed greater to sentences utterances as compared to consonants. Thus, for successful communication with native speakers, teachers should attempt to find out students' problems in pronouncing English phonemes, especially for vowels. A vital starting point of vowel instruction was best to use a limited quantity of vowel contrasts and then gradually requested learners to differentiate the whole scope of vowels (Celce-Murcia, Briton, Goodwin, \& Griner, 2010). From many previous vowel-contrast studies, a fairly common belief is that L2 learners have more difficulties with perception and production of front vowel pairs $/ \varepsilon /-/ \mathfrak{x} /$ than $/ \mathrm{i} / / / /$ / (Bion, Escudero, Rauber, \& Baptista, 2006) and L2 learners went through a higher degree of overreliance on duration in $/ \varepsilon /-/ \mathfrak{a} /$ than in $/ \mathrm{i} /-/$ / (Makarova, 2010). However, whether non-native speakers from different regions also have the same pronunciation problems should be examined and confirmed. Consequently, the current study focus on students' perception and production of front vowel contrasts /i//// / and / $\varepsilon /-$ æ/ at the syllable level (CVC).

In light of these concerns above, the purpose of the study was to compare the extent of difficulties in perceiving and producing the two front vowel pairs /i//// / and / $\varepsilon /-/ æ /$ by Taiwanese EFL learners. Moreover, the separated acoustic performance of $/ \mathrm{i} /, / / /, / \varepsilon /$ and $/ \mathfrak{x} /$ on perception and production was also explored. The current study also aimed to identify the extreme natures of $/ \mathrm{i} / / / / /$ and $/ \varepsilon /-/ \mathfrak{a} /$ perception-production links by Taiwanese EFL learners through minimal-pair tests. Therefore, two aspects were probed: (a) the different performance of $/ \mathrm{i} / / / \mathrm{l} / \mathrm{and} / \varepsilon /-/ \mathfrak{x} /$ on perception and production tasks; (b) the link between perception and production performance of $/ \mathrm{i} / / / \mathrm{l} /$ and $/ \varepsilon /-/ \mathfrak{x} /$. 
The present study would contribute to English phonemes teaching and learning. Many previous researchers have explored the performance of distinct vowels and consonants perception and production. In this study, it was expected that the findings would help English teachers identify more pronunciation problems and provide better phonetic instruction for students. Apart from that, students' acoustic and auditory improvement would also be anticipated to directly and indirectly influence their English communication skills. However, very little work has been conducted to compare front vowel pairs. In order to determine the difficulties with and the relationship between /i/-// / and / $\varepsilon /-/ æ /$ perception and production by EFL learners in Taiwan, the study was designed to answer the following questions :

1. How do EFL learners in Taiwan perform in their perception and production of English front vowel pairs /i/-/I / and $/ \varepsilon /-/ æ /$ ?

2. How is the perception of the English vowel pairs /i/-// / and /ع /-/æ/ correlated with their accurate production?

\section{LITERATURE REVIEW}

\section{A. Acoustic Properties of English Front Vowels}

NAE (North American English) comprised at least fourteen stressed vowels in which eleven were simple or vowelplus-glide vowels (/iy/, / /, /ey/, / $/$ /, /æ/, /a/, /^/, / /, /ow/, / /, /uw/) and three were diphthongs (/ay/, /aw/, /o y/) (Celce-Murcia, Briton, Goodwin, \& Griner, 2010). Four useful dimensions they mentioned to discriminate vowel sounds were: (1) the articulation degree of vowel-plus-glide vowel sounds; (2) the articulation place within the oral cavity of vowel sounds; (3) the articulation position of the tongue; (4) the articulation quality of vowel sounds. According to their vowel categorization, based on the 'NAE vowel quadrant', five front vowels were /iy/ (high front), // / (high front), /ey/ (mid front), / $\varepsilon /($ mid front) and /æ/ (low front). Among the front vowels, categorized by the extent of muscle tension, /iy/ and /ey/ were tense vowels which could take place in both stressed open and closed syllables. / /, $/ \varepsilon /$ and $/ æ /$, however were lax vowels which could occur only in closed syllables. Another acoustic feature of tense vowels was with longer duration than lax vowels except /æ/ (Reetz \& Jongman, 2009).

\section{B. Acquisition of English Vowel Contrasts}

The acquisition of vowel contrasts were probed from two domains: perception and production by Bion, Escudero, Rauber, and Baptista (2006). Seventeen English Language and Literature majors at a Brazilian university took part in the study. Besides, six female native English speakers participated as a comparison group. The study involved three main experiments. In the first experiment, four front vowels $(/ \mathrm{i} /, / / /, / \varepsilon /, / \mathfrak{l} /)$ embedded in four monosyllabic words which began with one of [p, b, f, s, k, g, h], ended in [t], and were contextualized in sentences (e.g., The past tense of the verb bite is _..) were employed to test learners' vowel production. In the second experiment, a Categorical Discrimination Test (CDT), in which native speakers pronounced the words formed by the insertion of one of the English vowels into a /bVt/ frame and articulated the words at the end of the carrier sentence "This is a " was utilized to test learners' category formation. Third, two edited-speech continua for $/ \mathrm{i} /-/ / /$ and $/ \varepsilon /$-/æ/ contrasts were used to test learners' spectral quality. From the results, it was concluded that for the speakers of Brazilian Portuguese, differentiating between the members of the vowel pair $/ \varepsilon /$ /æ/ $/$ was more difficult than between those of /i/-// / whereas for English native speakers, discriminating both contrasts was performed in parallel. The results also suggested that a positive correlation was found between vowel perception scores and vowel production vowels $(\mathrm{r}=.5, \mathrm{p}<.01)$, implying that vowel perception premised the accuracy of vowel production.

\section{The Relationship between Perception and Production of English Vowels}

L2 sound perception and production resembled a coin with two sides, for the scarcity of either domains would make communication difficult and incomplete (Ho, 2009). Many empirical studies had demonstrated a close link between perception and production. One study conducted by Baker and Trofimovich (2006) was to detect how perception and production of L2 vowels were correlated and what individual differences factors might influence the perceptionproduction link. Forty Korean learners of English were engaged in the study. Besides, ten native English speakers participated as a comparison group. In the study, six vowels $(/ \mathrm{i} /, / \mathrm{/} /, / \mathrm{u} /, / \mho /, / æ /, / \varepsilon /)$ placed in eighteen monosyllabic words with the English bilabial plosive /b/ and the glottal fricative /h/ were used for speech perception and production tasks. The results revealed that learners' AOA (age of arrival) had a better prediction on learners' perception and production performance than learners' LOR (length of residence). One vital finding was that a strong relationship between perception and production of L2 vowels was yielded $(\mathrm{r}(38)=.73, \mathrm{p}<.001$, two-tailed). Another study using comparisons of vowel pairs to examine whether individual perceptual variation could be correlated with their different production was administered by Fox (1982). In the study, three men and three women participated as the group of speakers. Moreover, sixteen nonlinguistic subjects took part in the study as the group of listeners. Experimental materials were thirty-six pairs from the vowel set $/ \mathrm{i} /, / / /, / \mathrm{u} /, / \mho /, / æ /, / \varepsilon /, / \mathrm{o} /, / \mathrm{a} /$ and $/ \wedge /$. The analysis data revealed that such perceptual variation was associated with individual's vowel articulation features, like the height of tongue and a systematic relationship could also be observed between perception and production of vowels in the study.

However, some divergence regarding the perception-production link has been expressed. A less consistency between perception and production of nonnative speakers than of native speakers was proven by Hoopingarner (2004). Eighty- 
seven native speakers of English and twenty-seven Korean nonnative speakers of English took part in the study. Internet and a computer-based instrument were used for the data collection. All of the tasks were performed by the participants in the same order. The first task was related to vowel sounds identification. These vowel sounds which needed to be identified were /i/, / /, /u/, / /, /æ/, / $\varepsilon /, / \mathrm{o} /, / \mathrm{a} /, / \wedge /$, /ə/ and /e/. The second task was related to word lists articulation. These listed words were heat, hit, hate, pet, and so on. From the study, one important finding was that for the nonnative groups, / / sound was statistically indistinguishable from /i/. It was concluded that the closer perception-production link occurred in native speakers than in nonnative speakers, due to new L2 vowel categories never formed by nonnative speakers.

\section{Methodology}

\section{A. Subjects}

In the elementary school at which the researcher taught, there were three Grade $6^{\text {th }}$ classes. Twenty students among them were randomly chosen to take part in the study. Of these twenty students whose average age was eleven, ten were female and ten were male. One additional 45-year-old male native speaker was employed to produce the stimuli.

\section{B. Instruments}

Based on the research design, there were three instruments used in the study. The stimuli, perception and production tests were administered for all participants in the study. Finally, in the data analyzing phase, paired sample t-tests and correlation analyses were used. The stimuli of the four front vowels (/i/, / /, / $\varepsilon /$, /æ/) embedded in ten monosyllabic words respectively for perception and production tests were used. The stimuli of front vowel pairs $/ \mathrm{i} /-/ / /$ and $/ \varepsilon /-/ æ /$ were provided through minimal pairs (e.g., beat /bit/- bit /bı t/) to highlight the only one different phonological element for participants to perceive and produce. The perception test included forty question items. Each question item was involved in two alternatives of $/ \mathrm{i} /$ and $/ / /$ or $/ \varepsilon /$ and $/ æ /$ for participants to choose. Among them, twenty items from question one to question twenty were related to /i/-/ı / pair and other twenty items from question twenty-one to question forty were related to $/ \varepsilon /-/ æ /$ pair. Each question item values one point. Thus, the highest points that the participants could get were forty points. With regard to the production test, it included twenty question items. Each question item was involved in two monosyllabic words of $/ \mathrm{i} /$ and $/ / /$ or $/ \varepsilon /$ and $/ æ /$ for participants to produce. Among them, ten items from question one to question twenty were related to /i/-/ / pair and another twenty items from question twentyone to forty were related to $/ \varepsilon /-/ æ /$ pair. Each question item was worthy of two points. In other words, in each question item although the participants pronounce a word incorrectly first, they could still get one point if they pronounce the next word correctly. Thus, the highest points that the participants could get were forty points.

\section{Procedures}

The entire procedures administered in the study included two primary phases: perception test and production test. In the preparatory stage of the study, selecting the monosyllabic words of front vowel pairs and assigning participants randomly were required. All the participants were given the perception test for the first phase. For the perception test, twenty minutes were needed. The second phase was to broadcast the stimuli recorded in advance and ask participants to select the right vowel in each question item on the answer sheet. The production test too twenty minutes. For the detailed procedure, its overall outline was presented in Fig. 1.

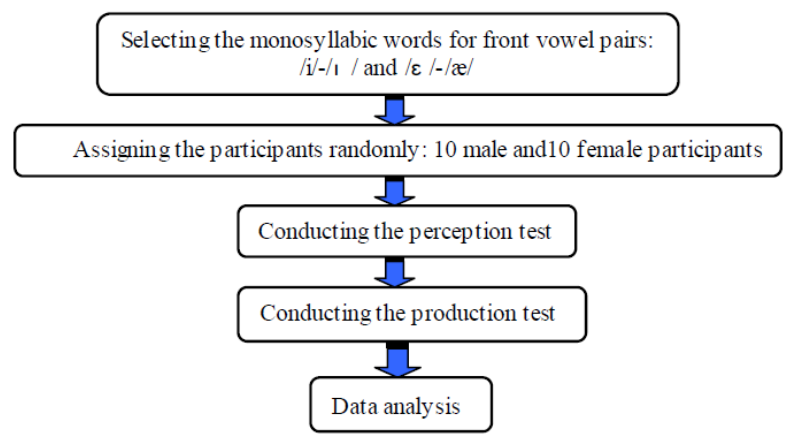

Figure 1. The procedure of the study design

\section{Data Analysis}

To investigate the research questions, the researcher used the statistical package SPSS to analyze the data collected from the perception and production tests. First, paired sample t-tests were administered for the perception and production tests scores respectively to see if there was a significant difference between these two front pairs /i/-// / and $/ \varepsilon /-/ æ /$. Second, paired sample t-tests were conducted for the perception and production tests scores to see if there was a 
significant difference between /i/ and / / or $/ \varepsilon /$ and /æ/. Third, correlation analyses were employed for the evaluation of the relationships between front vowel perception and production.

\section{RESULTS}

1. How do EFL learners in Taiwan perform in their perception and production of English front vowel pairs /i/-// / and $/ \varepsilon /-/ æ /$ ?

In order to determine the performance on perceiving and producing front vowel pairs, a paired sample t-test was administered at a selected probability level $(\alpha<.05)$. The data in Table 1 showed that the perception test scores means of $/ \mathrm{i} /-/ /$ / $(\mathrm{M}=16.85)$ was higher than that of $/ \varepsilon /-/ \Re /(\mathrm{M}=14.60)$. A statistical significant difference between /i/-/ / perception and $/ \varepsilon /-/ æ /$ perception was inspected $(\mathrm{t}(19)=2.408, \mathrm{p}=.026<.05)$. Moreover, the means of the production test scores of $/ \mathrm{i} /-/ / \quad /(\mathrm{M}=16.90)$ was also higher than that of $/ \varepsilon /-/ æ /(M=15.25)$. There was a significant production difference between $/ \mathrm{i} /-/ /$ and $/ \varepsilon /-/ æ /(\mathrm{t}(19)=3.343, \mathrm{p}=.003<.05)$. The statistical data were presented in Table 2 . The results indicated that $/ \varepsilon /-/ æ /$ pair was more difficult than $/ \mathrm{i} /$-// / pair for Taiwanese EFL learners in terms of perception and production.

TABLE 1

PERFORMANCE ON THE PERCEPTION OF FRONT VOWEL PAIRS $(\mathrm{N}=20)$

\begin{tabular}{lllllll}
\hline Categories & $\mathrm{N}$ & Mean & SD & t & df & Sig. \\
\hline$/ \mathrm{i} / / / / /$ & 20 & 16.85 & 2.54 & 2.408 & 19 & .026 \\
$/ \varepsilon /-/ æ /$ & 20 & 14.60 & 3.89 & & \\
\hline \multicolumn{7}{c}{ NOTE. $* \mathrm{P}<.05}$.
\end{tabular}

TABLE 2

PERFORMANCE ON THE PRODUCTION OF FRONT VOWEL PAIRS $(\mathrm{N}=20)$

\begin{tabular}{lllllll}
\hline Categories & $\mathrm{N}$ & $\mathrm{Mean}$ & $\mathrm{SD}$ & $\mathrm{t}$ & $\mathrm{df}$ & Sig. \\
\hline$/ \mathrm{i} /-/ / /$ & 20 & 16.90 & 1.92 & \multirow{2}{*}{3.343} & \multirow{2}{*}{19} & .003 \\
$/ \varepsilon /-/ æ /$ & 20 & 15.25 & 2.95 & & \\
\hline \multicolumn{7}{c}{ NOTE. $* \mathrm{P}<.05}$.
\end{tabular}

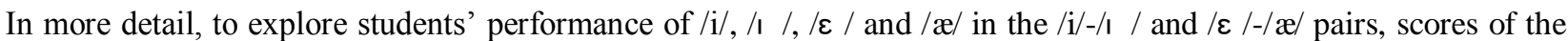
perception and production tests were computed and compared separately. In terms of perception, the score means of $/ \mathrm{i} /$ $(\mathrm{M}=8.7)$ was higher than that of $/ \mathrm{I} /(\mathrm{M}=8.15)$ while the score means of $/ \varepsilon /(\mathrm{M}=7.05)$ was lower than that of /æ/ $(\mathrm{M}$ = 7.45). A significant difference between $/ \mathrm{i} / \mathrm{and} / \mathrm{l} /(\mathrm{t}(19)=2.463, \mathrm{p}=.024<.05)$ was inspected. However, no significant difference yielded between $/ \varepsilon /$ and $/ \mathfrak{e} /(\mathrm{t}(19)=-.954, \mathrm{p}=.352>.05)$ in the perception tests. The detailed results were presented in Table 3 and Table 4.

TABLE 3

COMPARISONS OF THE PERCEPTION BETWEEN /I/ AND / / / $\mathrm{N}=20)$

\begin{tabular}{|c|c|c|c|c|c|c|}
\hline Categories & $\mathrm{N}$ & Mean & SD & $\mathrm{t}$ & $\mathrm{df}$ & Sig. \\
\hline /i/ & 20 & 8.7 & 1.42 & \multirow{2}{*}{2.463} & \multirow{2}{*}{19} & \multirow{2}{*}{.024} \\
\hline /1 / & 20 & 8.15 & 1.31 & & & \\
\hline \multicolumn{7}{|c|}{ NOTE. $* \mathrm{P}<.05$} \\
\hline \multicolumn{7}{|c|}{$\begin{array}{c}\text { TABLE } 4 \\
\text { COMPARISONS OF THE PERCEPTION BETWEEN / } / \text { / AND / } /(\mathrm{N}=20)\end{array}$} \\
\hline Categories & $\mathrm{N}$ & Mean & SD & $\mathrm{t}$ & $\mathrm{df}$ & Sig. \\
\hline$/ \varepsilon /$ & 20 & 7.05 & 1.93 & \multirow{2}{*}{-.954} & \multirow{2}{*}{19} & \multirow{2}{*}{.352} \\
\hline /æ/ & 20 & 7.45 & 2.28 & & & \\
\hline
\end{tabular}

Besides, in terms of production, the /i/ score means $(M=9.05)$ was higher than the / $/$ score means $(M=7.85)$ while the $/ \varepsilon /$ score means $(\mathrm{M}=8.70)$ was higher than $/ æ /$ score means $(\mathrm{M}=6.55)$. There were significant production differences between $/ \mathrm{i} /$ and $/ \mathrm{/} /(\mathrm{t}(19)=4.06, \mathrm{p}=.001<.05)$ and between $/ \varepsilon /$ and $/ \mathfrak{r} /(\mathrm{t}(19)=5.386, \mathrm{p}=.001<.05)$. Table 5 and Table 6 displayed the detailed results.

TABLE 5

COMPARISONS OF THE PRODUCTION BETWEEN/I/ AND / / $(\mathrm{N}=20)$

\begin{tabular}{|c|c|c|c|c|c|c|}
\hline Categories & $\mathrm{N}$ & Mean & SD & $\mathrm{t}$ & $\mathrm{df}$ & Sig. \\
\hline /i/ & 20 & 9.05 & .945 & \multirow{2}{*}{4.06} & \multirow{2}{*}{19} & \multirow{2}{*}{.001} \\
\hline /1 / & 20 & 7.85 & 1.348 & & & \\
\hline
\end{tabular}


TABLE 6

COMPARISONS OF THE PRODUCTION BETWEEN / $\mathcal{\varepsilon} /$ AND / $/(\mathrm{N}=20)$

\begin{tabular}{lllllll}
\hline Categories & $\mathrm{N}$ & Mean & SD & t & df & Sig. \\
\hline$/ \varepsilon /$ & 20 & 8.70 & 1.218 & 5.386 & 19 & .000 \\
$/ æ /$ & 20 & 6.55 & 2.114 & & \\
\hline \multicolumn{7}{c}{ NOTE. $*$ P $<.05}$.
\end{tabular}

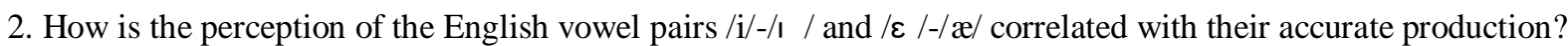

In order to examine the relationship between perception and production of front vowel pairs, correlational analyses were conducted. First, from the statistical data described in Table 7, a stronger linear relationship between perception and production of front vowel pairs was detected $(\mathrm{r}=.661, \mathrm{p}<.01)$. However, a weaker relationships between perception and production of $/ \mathrm{i} / / / \mathrm{l} /(\mathrm{r}=.354, \mathrm{p}=.126)$ and a stronger relationship between perception and production

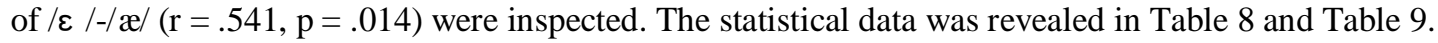

TABLE 7

CORRELATION MATRIX SUMMARY OF //I/-// / AND / $\varepsilon /-/ Æ /$ IN TERMS OF PERCEPTION AND PRODUCTION $(\mathrm{N}=20)$

\begin{tabular}{|c|c|c|c|c|c|c|}
\hline Categories & $\mathrm{N}$ & Mean & SD & $\mathrm{r}$ & $\mathrm{p}$ & $\mathrm{r}^{2}$ \\
\hline$/ \mathrm{i} /-/ /$ / and $/ \varepsilon /-/ æ /$ Perception & 20 & 31.45 & 5.06 & \multirow{2}{*}{$.661 *$} & \multirow{2}{*}{.002} & \multirow{2}{*}{.437} \\
\hline /i/-/ı / and / $\varepsilon /-/ æ /$ Production & 20 & 32.15 & 4.46 & & & \\
\hline
\end{tabular}

TABLE 8

CORRELATION MATRIX SUMMARY OF /I/-/i / IN TERMS OF PERCEPTION AND PRODUCTION $(\mathrm{N}=20)$

\begin{tabular}{lllllll}
\hline & $\mathrm{N}$ & $\mathrm{Mean}$ & $\mathrm{SD}$ & $\mathrm{r}$ & $\mathrm{p}$ & $\mathrm{r}^{2}$ \\
\hline /i/-// / Perception & 20 & 16.85 & 2.54 & \multirow{2}{*}{.354} & .126 & .125 \\
\hline /i//// / Production & 20 & 16.90 & 1.92 & & & \\
\hline
\end{tabular}

TABLE 9

CORRELATION MATRIX SUMMARY OF /E/-/Æ/ IN TERMS OF PERCEPTION AND PRODUCTION $(\mathrm{N}=20)$

\begin{tabular}{|c|c|c|c|c|c|c|}
\hline & $\mathrm{N}$ & Mean & SD & $\mathrm{r}$ & $\mathrm{p}$ & $\mathrm{r}^{2}$ \\
\hline /દ /-/æ/ Perception & 20 & 14.60 & 3.89 & \multirow{2}{*}{$.541^{*}$} & \multirow{2}{*}{.014} & \multirow{2}{*}{.293} \\
\hline /દ /-/æ/ Production & 20 & 15.25 & 2.95 & & & \\
\hline
\end{tabular}

\section{DISCUSSION}

\section{A. Performance on Two English Front Vowel Pairs}

The study sought to detect the different performance and difficulties in perceiving and producing front vowel pairs

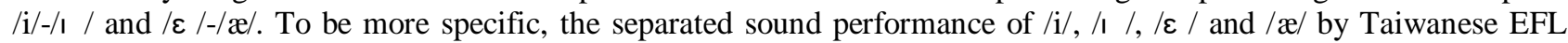
learners was also explored individually. The results revealed that there was a significant mean difference between the/i/-

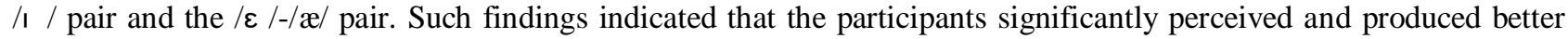
$/ \mathrm{i} / / / \mathrm{l} /$ pair than $/ \varepsilon /-/ \mathfrak{x} /$ pair. In other words, the results suggested that for Taiwanese EFL learners, making discrimination between the members of the vowel pair $/ \varepsilon /$ /æ/ $/$ was more difficult than those of $/ \mathrm{i} /$ // $/$. This result was accordant with the findings of Bion, Escudero, Rauber, \& Baptista (2006) in which the difference in a correct discrimination between these two vowels contrasts $/ \mathrm{i} / / / / /$ and $/ \varepsilon /-/ \mathfrak{x} /$ was highly significant. Another interesting finding was observed that more than half participants attempted to underscore the distinctions between $/ \mathrm{i} /$ and $/ \mathrm{s} /$ or $/ \varepsilon /$ and /æ/ by using vowel over-duration, especially for $/ \varepsilon / /$ / / pair more than $/ \mathrm{i} / / / \mathrm{l} /$ pair. The finding was consistent with the results of Makarova's study (2010). The possible reason was that learners had greater difficulties with the perception and the production of $/ \varepsilon /-/ \mathfrak{a} /$ pair than that of /i//// / pair. Therefore, they overused the duration skill of vowels. This study also aimed to explore students' performance of reception and production on individual front vowels: /i/, / /, / $/$ / and /æ/. As the results indicated, the participants perceive and produce significantly better /i/ sound than / / sound. In addition, the participants had significant better performance in producing / $\varepsilon /$ sound than $/ \mathfrak{x} /$ sound, however the same performance was not found in perceiving / $\varepsilon /$ sound and /æ/ sound. Conversely, the perception of $/ \varepsilon /$ was slightly worse than that of /æ/. The reason could be due to that learners should spread and lower their lips to articulate $/ \mathfrak{x} /$ sound more than $/ \varepsilon /$ sound. Thus, for EFL learners, /æ/ sound was more difficult to pronounce, but was easier to perceive because of the lip-spreading feature of the specific sound. On the other hand, the results of worse / / performance on perception and production than /i/ support the view of Hoopingarner (2004) that / / sound was statistically indistinguishable from /i/. Another direct distinction between /i/ and / / was that /i/ was a tense vowel with more muscle tension for making perception and production more distinguishable. 


\section{B. Perception-production Link of English Front Vowel Pairs}

The study tried to explore how the perception of English vowel pairs /i/-// / and / $\varepsilon /-/ æ /$ correlated with their accurate production. For confirming the exact nature of the relationship, correlational analyses were administered in detail to detect it. The results of the current study revealed a positive relationship between perception and production test scores. In other words, the positive nature showed there was a closer correlation between perception and production of English vowels, corresponding to the previous research results (Baker \& Trofimovich, 2006; Fox, 1982). However, although the perception had a positively stronger correlation with the production in terms of these two front vowel pairs, the separated perception-production link of /i/-// / was weaker. That is to say, for /i/-// /, the prediction of perception on its accurate production could not be powerfully expected, directly surpporting the validity of the results of research question one. However, the computation of perception-production link of $/ \varepsilon /-/ æ /$ yielded differential outcome. The perception and production of $/ \varepsilon /$-/æ/ possesses a stronger link. In other words, students who have higher scores on $/ \varepsilon /-$ $/ æ /$ perception tests tend to get higher scores on $/ \varepsilon /-/ æ /$ production tests.

\section{CONCLUSION}

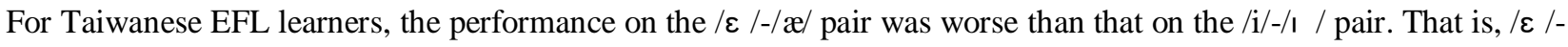
/æ/ pair was more difficult for EFL Taiwanese learners to acquire not only in perception but also in production. For the performance on the individual sound of these four front vowels, the perception of /i/ was significantly better than that of / /. The perception of /æ/ was slightly better than that of $/ \varepsilon /$ although no significant difference between them was

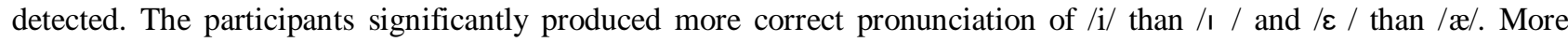
importantly, a stronger positive relationship between perception and production of these two front vowel pairs was proven although the perception-production link was weaker in terms of /i/-// / pair while it was stronger in terms of / $\varepsilon$ //æ/ pair.

\section{Pedagogical Implications}

From the study, two pedagogical implications were provided. First, for the instruction of these two front vowel pairs, English teachers should pay more attention to teach students how to discriminate both pairs, especially for the / $\varepsilon /-/ æ /$ pair. The findings of the current study implied that among the four front vowels, $/ \varepsilon /$ was the most difficult sound in terms of perception and /æ/ was the most difficult sound in terms of production. The instructors should notice these vital findings and involve students in the instruction about how to distinguish the involvement and the height of tongue position when perceiving and producing the vowels for successful EFL learning. Second, as we know, a positive correlation existed between English vowel perception and production. During the acquisition of the phonetic system, no matter for instructors or learners, these two language skills perception and production should be emphasized and acquired, not merely for communication goals. Instructors should duly modulate their teaching method and procedure when necessary to provide learners with more articulation practice to overcome perception and production difficulties for language enhancement.

\section{SUGGESTIONS FOR FUTURE STUDIES}

Further researches should enlarge the sample size to detect the performance of these two front vowel pairs more precisely. Furthermore, the research scope of English vowels should contain other pairs, such as /u/-/v/, or other simple vowels and diphthongs to examine whether different outcomes exist.

\section{REFERENCES}

[1] Best, C. T. (1991). The emergence of native-language phonological influences in infants: A perceptual assimilation model. In J. C. Goodman \& H. C. Nusbaum (Eds.), The development of speech perception: The transition from speech sounds to spoken words (pp. 167-223). Cambridge, MA: MIT Press.

[2] Bion, R., Escudero, P., Rauber, A. S., \& Baptista, B. (2006). Category formation and the role of spectral quality in the perception and production of English front vowels. Proceedings of Interspeech 2006. Pittsburgh, United States.

[3] Baker, W., \& Trofimovich, P. (2006). Perceptual paths to accurate production of L2 vowels: the role of individual differences. International Review of Applied Linguistics in Language Teaching, 44(3), 231-250. http://dx.doi.org/10.1515/IRAL.2006.010

[4] Celce-Murcia, M., Briton, D. M., Goodwin, J. M., \& Griner B. (2010). Teaching pronunciation. New York, USA: Cambridge University Press.

[5] Fogerty D., \& Humes L. E. (2011). The role of vowel and consonant fundamental frequency, envelope, and temporal fine structure cues to the intelligibility of words and sentences. Acoustical Society of America, 131(2), 1490-1501. http://dx.doi.org/10.1121/1.3676696.

[6] Fox, R. A. (1982). Individual variation in the perception of vowels: implications for a perception-production link. Phonetica 39, 1-22. http://dx.doi.org/10.1159/000261647

[7] Ho, Y., (2009). The perception and production of American English front vowels by EFL learners in Taiwan: the influence of first language and proficiency levels. Dissertation Abstracts International, 70(09), A. (AAT3372354).

[8] Hoopingarner, D. (2004). Native and nonnative differences in the perception and production of vowels. Dissertation Abstracts International, 65(04), A. (AAT3129492). 
[9] Liao, J. (2006). English vowel production of mandarin speakers. Dissertation Abstracts International, 69(10), A. (AAT333522).

[10] Lin, M. (1995). Production of five American English front vowels by adult mandarin Chinese speakers. Dissertation Abstracts International, 56(11), A. (AAT9608775).

[11] Makarova, A. O. (2010). Acquisition of three vowel contrasts by Russian speakers of American English. Dissertation Abstracts International, 71(07), A. (АAT3415420).

[12] Reetz, H., \& Jongman, A. (2009). Phonetics: transcription, production, acoustics and perception. Chichester, UK; Malden, MA: Blackwell.

Ching-Ying Lin is an assistance professor of Applied English Department and the director of international Cooperation Section, National Pingtung Institute of Commerce, R.O.C. She obtained her Ed. D. degree in the bilingual education from Texas A \& M University, U.S.A. Her specialties are Second Language Acquisition, Learning Strategies, Curriculum Design and ComputerAssisted Language Learning. 